\title{
Effects of a New Set of Computed Additive Parameters on the Rate of $\mathrm{SN}^{2}$ Substitution Reactions
}

\author{
Mahmmoud Saieed \\ Department of Chemistry / College of Education \\ University of Mosul
}

Received

04 / 05 / 2009
Accepted

13 / 05 / 2009

\section{الخالصة}

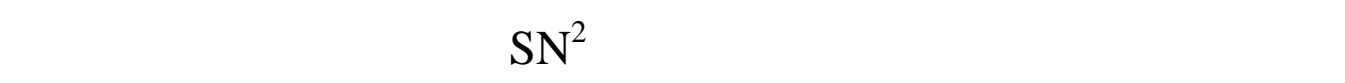

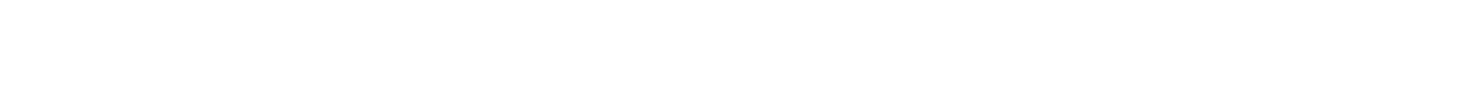

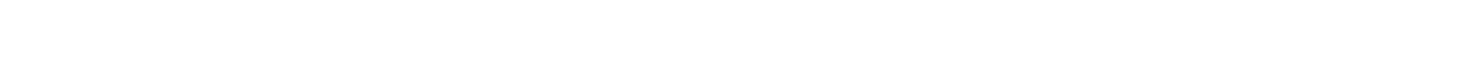

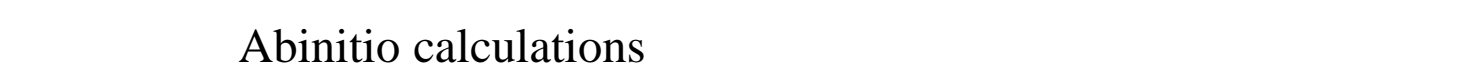

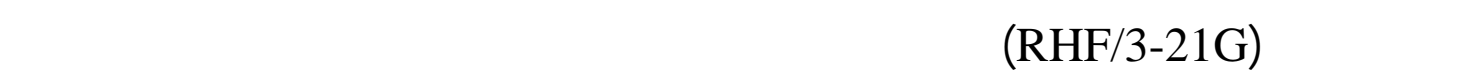

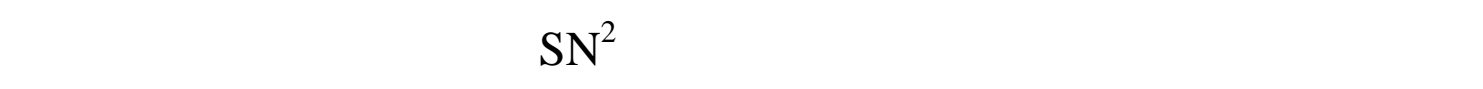
الحلمضية في المحيط ألحلمضي.

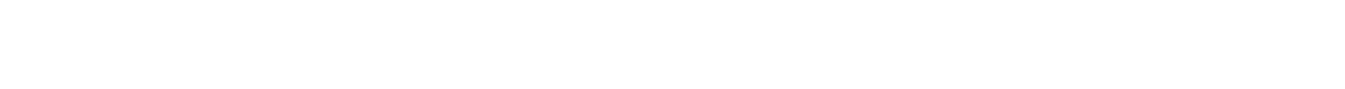

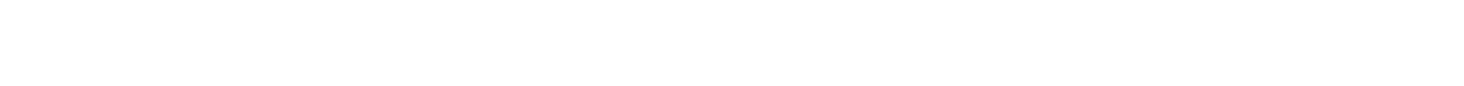
وان هذه النتيجة جاعت مقاققة مع الأدبيت الكيميائية مما يؤكدسلامة التسابلت الت مي ت م

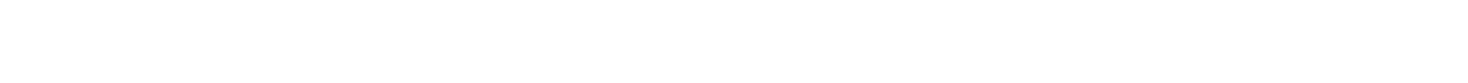
المجموعة الالكيلية المرتطة بمجموعة الأمبنها،

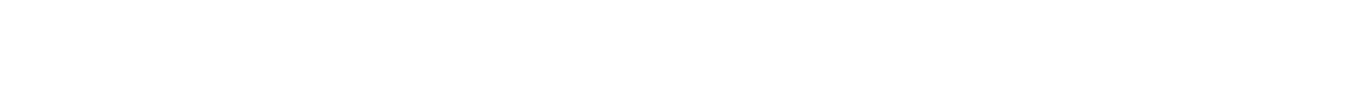

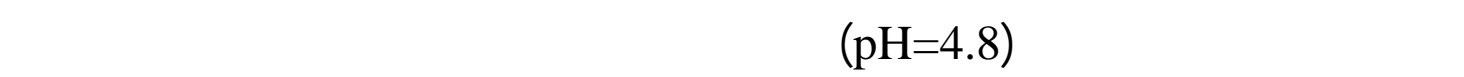

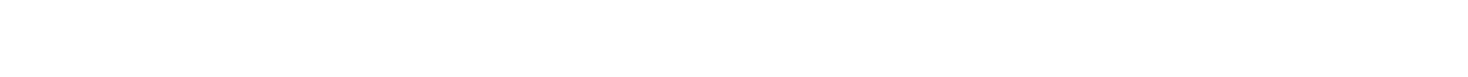

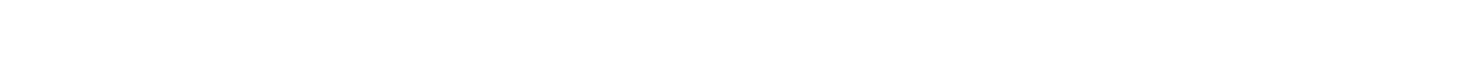
للمركب مع ثابت اللسرعة تأثير محدود.

\section{ABSTRACT}

A guide by the idea that the rate of $\mathrm{SN}^{2}$ substitution reactions are highly affected by the charge of the atoms at or near to the reaction center 
together and the bond length between carbon atom and the leaving group. Also the total strain energy of reacting molecules has great effects on the reaction rate. The present work employed high level ab nitio calculation (RHF/3-21G) in order to calculate the above parameters for a set of fifteen bromoalkyl amines undergoing. $\mathrm{SN}^{2}$ replacement reaction of the bromide ion by hydrogen thiosulphate ion in acidic medium.

The results of these calculations showed that the alkyl substituent at the amino group has pronounce effects on the charge value at the atoms of the molecules at or near the reaction center. On the other hand, the total strain energy of the molecules increases, as the bulkiness of the $\mathrm{N}$ substituents and chain length of alkyl amine increase which prove that these theoretical calculations are in accordance with the well known chemical principle. A simple correlation of the above parameters with experimental values of the rate constant for the substitution reactions at $\mathrm{pH}$ equal to 4.9 showed a good relation with charge at the carbon atom attached to the leaving group as well as the charge at the leaving group. While the $\mathrm{C}-\mathrm{Br}$ bond length and total strain energy showed no significant effects on the reaction.

\section{INTRODUCTION}

In the recent years the theoretical calculations have gained a lot interest due to the fast development in computing facilities (1-4) which lead to the easiness in calculating many physical properties for organic molecules. On the other hand, the reliability and realness of these calculations can be estimated by correlation of these calculated properties with some experimental values such as $\mathrm{pK}$ for the molecules under investigation (5).

Recently the rate constants for the $\mathrm{SN}^{1}$ substitution reaction of bromide group by thiosulphate in a basic medium have been correlated with some theoretically calculated physical properties of the reacting molecules (6).In the present work the rate constants for the same reaction in an acidic medium are correlated with some theoretically calculated physical properties of the reacting molecules, such as electron density at reaction center, bond length between the carbon atom and leaving bromide atom, together with the total strain energy of the reacting molecules.

\section{METHOD}

All the values of the rate constants were taken from our previous ref. (7). The geometries of fifteen bromoalkyl amines were optimized using ab nitio calculations. These calculations were performed with GAMESS software, at the restricted Hartree-Fock level by using standard $(3-21 G)$ basis set. These optimized geometries were then used to compute 
the charge on the carbon and bromide atoms, bond length coupled with the total strain energy, using molecular mechanic method (MM2). The correlation has been done using the following equation

$$
\mathrm{Y}=\mathrm{a}+\mathrm{b}_{1} \mathrm{x}_{1}+\mathrm{b}_{2} \mathrm{X}_{2}+---------\mathrm{b}_{\mathrm{n}} \mathrm{x}_{\mathrm{n}}
$$

Where $\mathrm{y}$ is a dependent variable represent the rate for the reaction, $a$ is a reference constant and $b_{1}, b_{2}---b_{n}$ are the coefficient of the independent variable $\mathrm{x}_{1}, \mathrm{x}_{2}---\mathrm{X}_{\mathrm{n}}$

\section{RESULT AND DISSCOSION}

The reaction between the hydrogen thiosulphate ion and bromoalkylamines in an acidic medium is proceeded (8) via $\mathrm{SN}^{2}$ mechanism as shown in the following scheme:

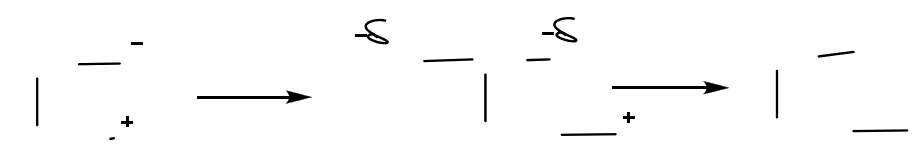

It is clear from the above scheme that the reaction is proceeded by a direct attachment of the hydrogen thiosulphate ion on the methylene group. According to the above mechanism one can expect is the rate of reaction is highly dependent on the electronic properties of the atom at or near to reaction center. One of these important (5)properties are the charge at the carbon atom attached to the bromide atom together with charge on the bromide atoms. On the other hand, the bond length of $\mathrm{C}$ $\operatorname{Br}(2)$ and the total strain energy of the reacting molecules were calculated. These results are shown in Table I.

Table I: The calculated physical properties of some bromoalkylamines

\begin{tabular}{|c|c|c|c|c|}
\hline Compounds & $\begin{array}{l}\text { Charge at } \\
\text { the C- } \\
\text { attached } \mathrm{Br}\end{array}$ & $\begin{array}{c}\text { Charge } \\
\text { at } \mathrm{Br}\end{array}$ & $\begin{array}{c}\mathrm{C}-\mathrm{Br} \\
\text { bond } \\
\text { length } \mathrm{A}^{\mathrm{o}}\end{array}$ & $\begin{array}{c}\text { Strain } \\
\text { energy } \\
\mathrm{K} \text { cal/mole }\end{array}$ \\
\hline Bromoethylamine & -0.7186 & 0.1948 & 1.933 & 3.588 \\
\hline $\mathrm{N}, \mathrm{N}$-dimethyl derivative & -0.6943 & 0.1237 & 1.983 & 9.425 \\
\hline N,N-diethyl derivative & -0.7003 & 0.1551 & 1.981 & 11.719 \\
\hline $\mathrm{N}, \mathrm{N}$-diisopropyl derivative & -0.6997 & $0.1+13$ & $1.9 \mathrm{Bz}$ & 26.322 \\
\hline Bromopropylamine & -0.6623 & $0.1338^{2}$ & 1.9786 & 4.692 \\
\hline $\mathrm{N}, \mathrm{N}$-dimethyl derivative & $\mathrm{J}_{30.6566^{+}}$ & 0.1187 & 1.9805 & 7.992 \\
\hline N,N-diethyl derivative & -0.6573 & 0.1138 & 1.9812 & 24.182 \\
\hline $\mathrm{N}, \mathrm{N}$-diisopropyl derivative & -0.6523 & 0.1060 & 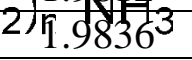 & 32.953 \\
\hline Bromobutylamine & -0.6449 & 0.0938 & 1.9437 & 6.810 \\
\hline $\mathrm{N}, \mathrm{N}$-dimethyl derivative & -0.6405 & 0.0829 & 1.9874 & 13.478 \\
\hline $\mathrm{N}, \mathrm{N}$-diethyl derivative & -0.6406 & 0.0797 & 1.9862 & 20.453 \\
\hline $\mathrm{N}, \mathrm{N}$-diisopropyl derivative & -0.6367 & 0.0745 & 1.9889 & 33.8841 \\
\hline Bromopentylamine & -0.6377 & 0.0674 & 1.9883 & 5.3672 \\
\hline Bromohexylamine & -0.6312 & 0.0499 & 1.9914 & 5.8638 \\
\hline Bromoheptylamine & -0.6260 & 0.0371 & 1.9937 & 6.4215 \\
\hline
\end{tabular}


Firstly we tried to find the relation between the structure of the reacting molecules with the calculated physical properties. These results pointed out that the charge at the carbon atom of methylene group attached to the bromide atom decreases as the substituent size on the amino group varies from hydrogen to isopropyl group Figure I a. On the other hand, there is a pronounce decrease in the charge at the carbon atom as the number of ethylene groups increased in the molecules. Figure I b

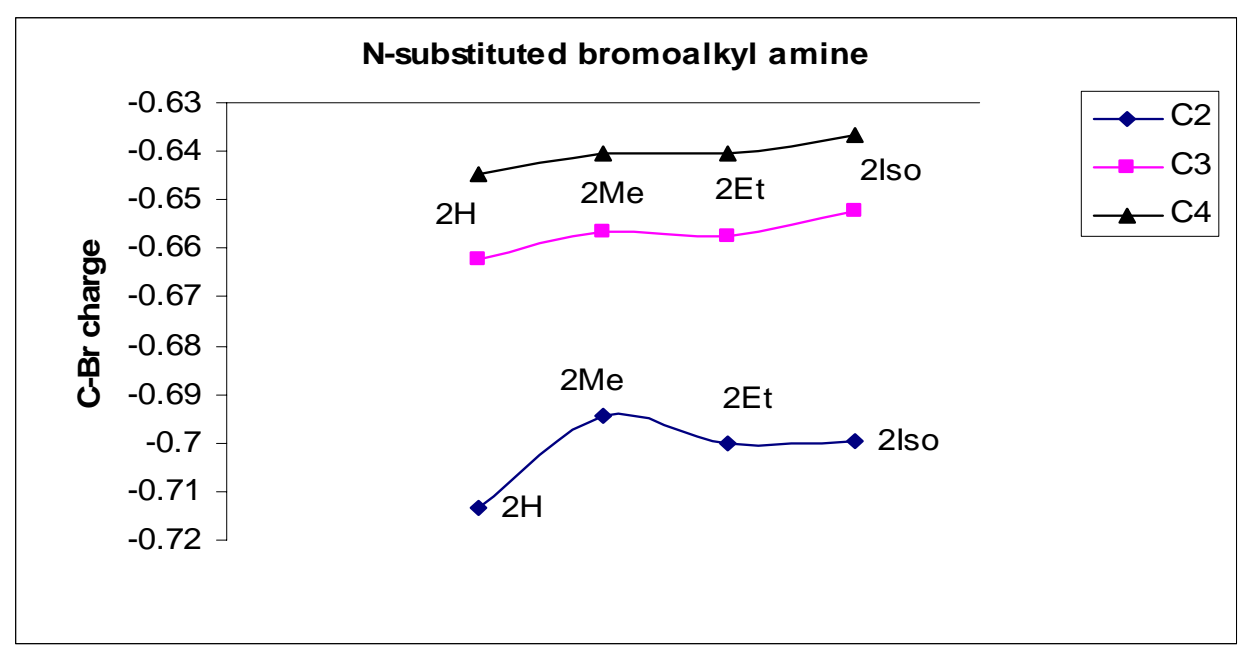

Figure I (a)

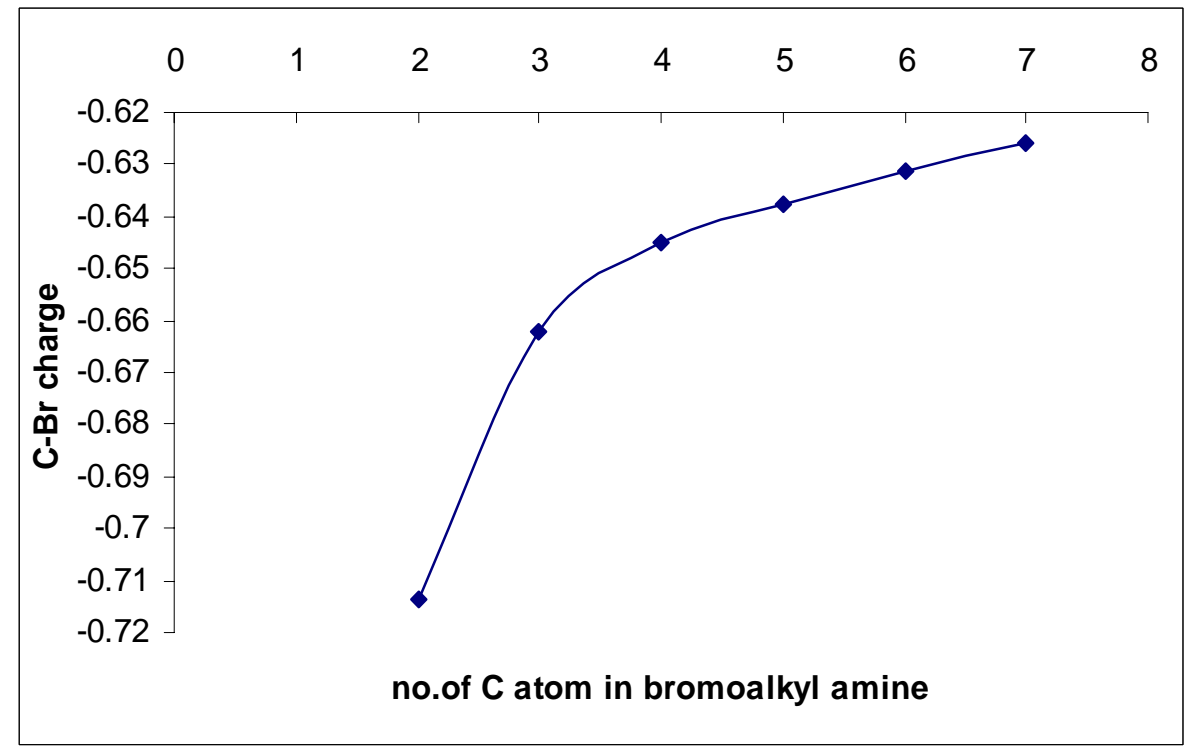

Figure I (b)

Figure I (a ,b) Shows the variation of the charge at the carbon atom adjacent to the bromide atom.

The charge at the bromide atoms showed a little variation on changing the substituent at the amino group and changing the length of the reaction molecules. Figure II 


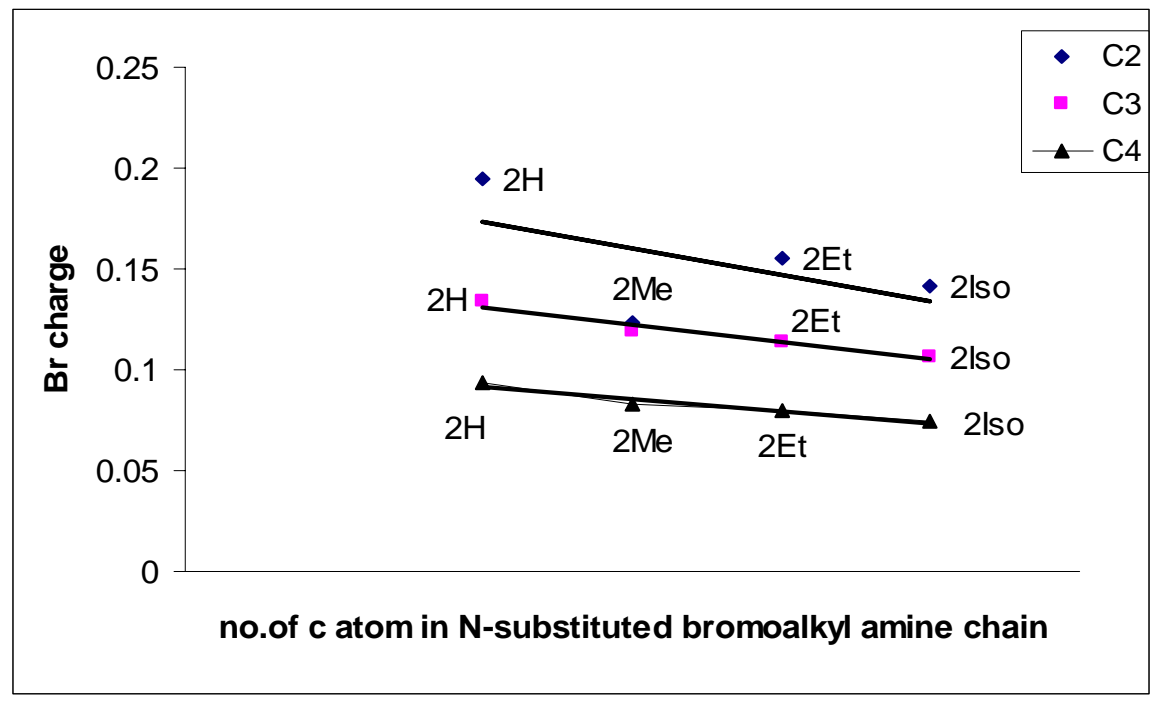

Figure II shows the charge variations of the bromide atom

The calculations of the total strain energy of the molecules revealed that the energy increased as the bulkiness of alkyl substituted at the amino group increased while the length of the molecules has litle effect on the energy as shown in Figure III.

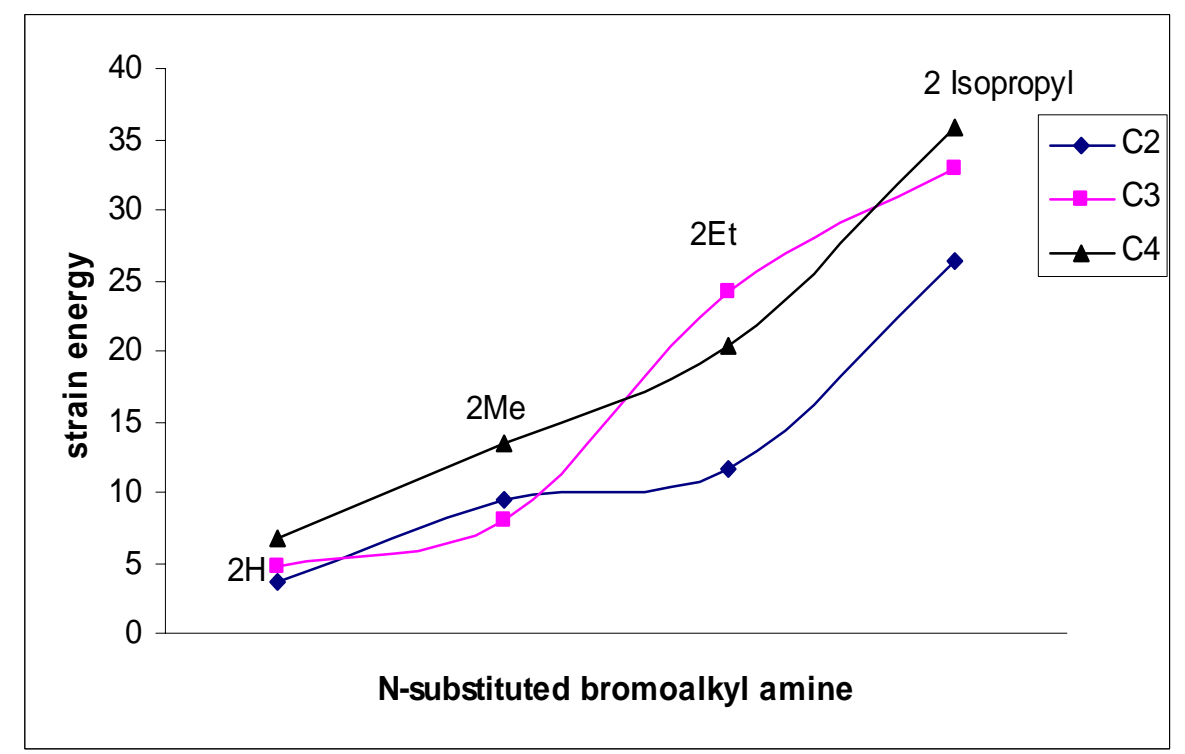

Figure III a 


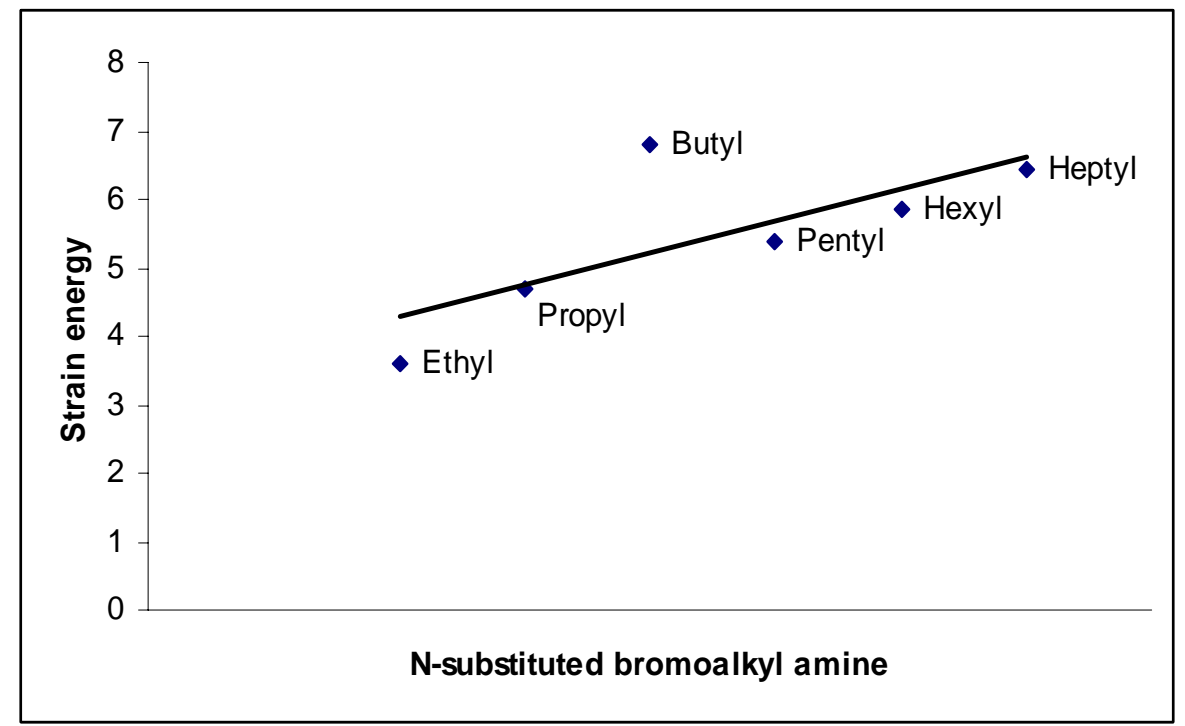

Figure III b

Figure III $(\mathbf{a}, \mathbf{b})$ shows the variation of strain energy of the reacting molecules

The variation of the $\mathrm{C}-\mathrm{Br}$ bond length with the bulkiness of the $\mathrm{N}$ substituted alkyl shown in Figure IV seems to be relatively small, specially for the bromopropylamine compound>

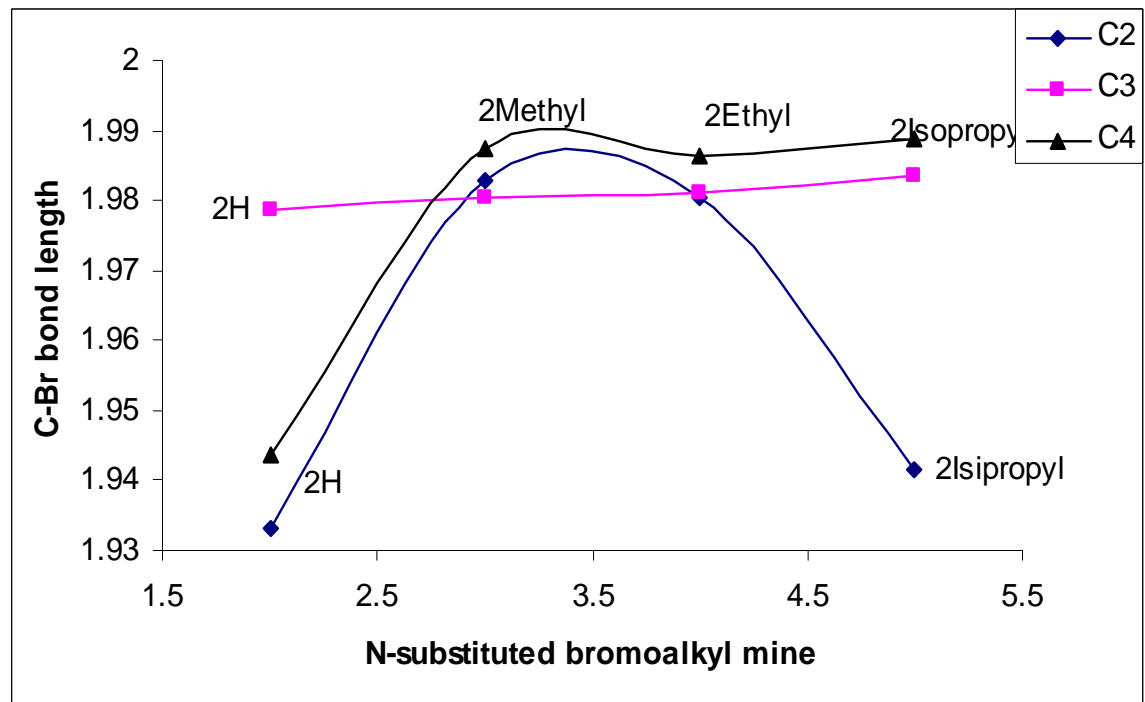

Figure IV a 


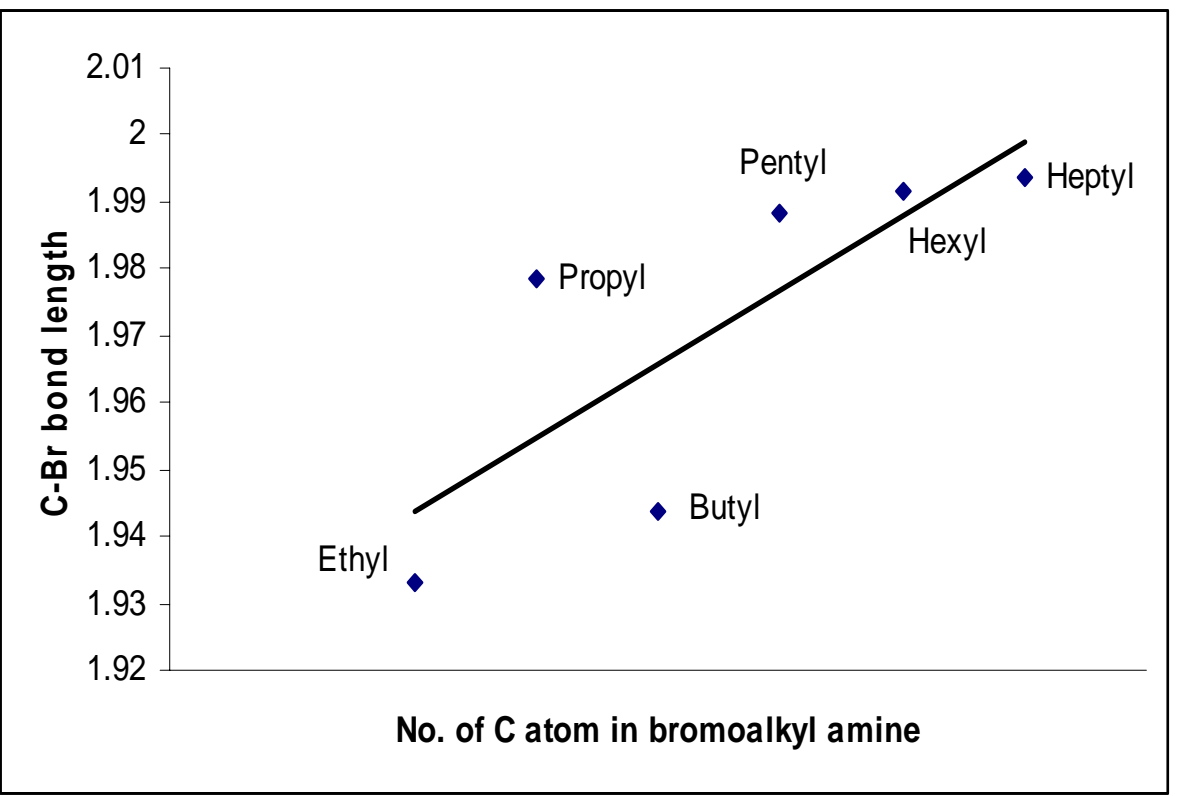

Figure IV b

Figure IV (a, b) :the variation of calculated C-Br bond length with the bulkiness of substituted alkyl

The above results showed that the variation of some calculated physical properties occured in the manner consistent with chemical intuition. Further more any success of these calculated properties can be ascertained by correlation of these calculated properties with some experimental values. So that the above calculated properties are singly correlated with rate constant of $\mathrm{SN}^{2}$ substitution reaction between hydrogen thiosulphate ion with bromoalkyl amines. The results obtained are listed in; Table II for N,N-disubstituted bromoethyl amine, Table III for N,N-disubstituted bromopropyl amine, Table IV for N,N-disubstituted bromobutyl amine and Table $\mathrm{V}$ for bromoalkyl amine.

Table II: Correlation analysis of selected parameter with experimental rate constant as a dependent variable for $\mathbf{N}$, $\mathbf{N}$-disubstituted bromoethyl amine

\begin{tabular}{|c|c|c|c|c|c|c|c|}
\hline parameters & $\mathbf{a}$ & $\mathbf{b}$ & $\mathbf{R}$ & $\mathbf{p a r a m e t e r s}$ & $\mathbf{a}$ & $\mathbf{b}$ & $\mathbf{R}$ \\
\hline *C-Br charge & $3.42 \mathrm{E}-3$ & $3.97 \mathrm{E}-3$ & 0.607 & $\begin{array}{c}\text { C-Br charge } \\
\text { S.E }\end{array}$ & $1.31 \mathrm{E}-3$ & $\begin{array}{c}1.08 \mathrm{E}-3 \\
6.27 \mathrm{E}-6\end{array}$ & 0.968 \\
\hline C-Br length & $2.00 \mathrm{E}-4$ & $2.18 \mathrm{E}-4$ & 0.82 & $\begin{array}{c}\text { C-Br charge } \\
\text { Br charge }\end{array}$ & $6.89 \mathrm{E}-3$ & $\begin{array}{c}9.33 \mathrm{E}-3 \\
1.92 \mathrm{E}-3\end{array}$ & 0.634 \\
\hline S.E & $5.41 \mathrm{E}-4$ & $6.87 \mathrm{E}-6$ & 0.958 & $\begin{array}{c}\text { C-Br length } \\
\text { S.E }\end{array}$ & $-5.78 \mathrm{E}-4$ & $\begin{array}{c}5.69 \mathrm{E}-4 \\
7.08 \mathrm{E}-6\end{array}$ & 0.981 \\
\hline Br charge & $8.24 \mathrm{E}-4$ & $-1.27 \mathrm{E}-3$ & 0.552 & $\begin{array}{c}\text { C-Br length } \\
\text { Br charge }\end{array}$ & $3.51 \mathrm{E}-3$ & $\begin{array}{c}-1.3 \mathrm{E}-3 \\
-2.01 \mathrm{E}-3\end{array}$ & 0.665 \\
\hline $\begin{array}{l}\text { C-Br charge } \\
\text { C-Br length }\end{array}$ & $1.08 \mathrm{E}-2$ & $\begin{array}{c}8.13 \mathrm{E}-3 \\
-2.28 \mathrm{E}-3\end{array}$ & 0.828 & $\begin{array}{c}\text { S.E } \\
\text { Br charge }\end{array}$ & $5.76 \mathrm{E}-4$ & $\begin{array}{c}6.56 \mathrm{E}-6 \\
-1.99 \mathrm{E}-4\end{array}$ & 0.961 \\
\hline
\end{tabular}


Table III :Correlation analysis of selected parameter with experimental rate constant as a dependent variable for $\mathrm{N}, \mathrm{N}$-disubstituted bromopropyl amine

\begin{tabular}{|c|c|c|c|c|c|c|c|}
\hline parameters & $\mathbf{a}$ & $\mathbf{b}$ & $\mathbf{R}$ & parameters & $\mathbf{a}$ & $\mathbf{b}$ & $\mathbf{R}$ \\
\hline$*$ C-Br charge & $2.30 \mathrm{E}-2$ & $3.43 \mathrm{E}-2$ & 0.963 & $\begin{array}{c}\text { C-Br charge } \\
\text { S.E }\end{array}$ & $1.43 \mathrm{E}-3$ & $\begin{array}{c}2.12 \mathrm{E}-2 \\
4.89 \mathrm{E}-6\end{array}$ & 0.998 \\
\hline C-Br length & -0.138 & $7.00 \mathrm{E}-2$ & 0.992 & $\begin{array}{c}\text { C-Br charge } \\
\text { Br charge }\end{array}$ & $5.44 \mathrm{E}-3$ & $\begin{array}{c}5.67 \mathrm{E}-3 \\
-1.04 \mathrm{E}-2\end{array}$ & 0.991 \\
\hline S.E & $3.02 \mathrm{E}-4$ & $1.02 \mathrm{E}-5$ & 0.936 & $\begin{array}{c}\text { C-Br length } \\
\text { S.E }\end{array}$ & -0.124 & $\begin{array}{c}6.26 \mathrm{E}-2 \\
1.22 \mathrm{E}-6\end{array}$ & 0.993 \\
\hline $\mathrm{Br}$ charge & $1.93 \mathrm{E}-3$ & $-1.23 \mathrm{E}-2$ & 0.990 & $\begin{array}{c}\text { C-Br length } \\
\text { Br charge }\end{array}$ & $-7.41 \mathrm{E}-2$ & $\begin{array}{c}3.80 \mathrm{E}-2 \\
-5.84 \mathrm{E}-3\end{array}$ & 0.999 \\
\hline $\begin{array}{c}\text { C-Br charge } \\
\text { C-Br length }\end{array}$ & -0.138 & $\begin{array}{c}6.60 \mathrm{E}-5 \\
6.99 \mathrm{E}-2\end{array}$ & 0.992 & $\begin{array}{c}\text { S.E } \\
\text { Br charge }\end{array}$ & $1.57 \mathrm{E}-3$ & $\begin{array}{c}2.62 \mathrm{E}-6 \\
-9.64 \mathrm{E}-3\end{array}$ & 0.996 \\
\hline
\end{tabular}

* charge on $\mathrm{C}$ attached to $\mathrm{Br}$

Table IV: Correlation analysis of selected parameter with experimental rate constant as a dependent variable for $\mathrm{N}, \mathrm{N}$-disubstituted bromobutyl amine

\begin{tabular}{|c|c|c|c|c|c|c|c|}
\hline parameters & $\mathbf{a}$ & $\mathbf{b}$ & $\mathbf{R}$ & parameters & $\mathbf{a}$ & $\mathbf{b}$ & $\mathbf{R}$ \\
\hline$*$ C-Br charge & $-1.06 \mathrm{E}-3$ & $-1.87 \mathrm{E}-3$ & 0.463 & $\begin{array}{c}\text { C-Br charge } \\
\text { S.E }\end{array}$ & $-7.10 \mathrm{E}-3$ & $\begin{array}{c}-1.12 \mathrm{E}-2 \\
2.65 \mathrm{E}-6\end{array}$ & 0.947 \\
\hline C-Br length & $1.13 \mathrm{E}-3$ & $-5.01 \mathrm{E}-4$ & 0.820 & $\begin{array}{c}\text { C-Br charge } \\
\text { Br charge }\end{array}$ & $2.52 \mathrm{E}-3$ & $\begin{array}{c}4.04 \mathrm{E}-3 \\
2.48 \mathrm{E}-3\end{array}$ & 0.575 \\
\hline S.E & $1.41 \mathrm{E}-4$ & $-1.71 \mathrm{E}-7$ & 0.159 & $\begin{array}{c}\text { C-Br length } \\
\text { S.E }\end{array}$ & $1.74 \mathrm{E}-3$ & $\begin{array}{c}-8.22 \mathrm{E}-4 \\
8.21 \mathrm{E}-7\end{array}$ & 0.99 \\
\hline $\mathrm{Br}$ charge & $6.62 \mathrm{E}-5$ & $8.70 \mathrm{E}-4$ & 0.528 & $\begin{array}{c}\text { C-Br length } \\
\text { Br charge }\end{array}$ & $2.92 \mathrm{E}-3$ & $\begin{array}{c}-1.31 \mathrm{E}-3 \\
-2.37 \mathrm{E}-3\end{array}$ & 0.998 \\
\hline $\begin{array}{c}\text { C-Br charge } \\
\text { C-Br length }\end{array}$ & $4.63 \mathrm{E}-3$ & $\begin{array}{c}3.89 \mathrm{E}-3 \\
-1.01 \mathrm{E}-3\end{array}$ & 0.954 & $\begin{array}{c}\text { S.E } \\
\text { Br charge }\end{array}$ & $-2.27 \mathrm{E}-4$ & $\begin{array}{c}2.16 \mathrm{E}-6 \\
3.90 \mathrm{E}-3\end{array}$ & 0.965 \\
\hline
\end{tabular}

* charge on $\mathrm{C}$ attached to $\mathrm{Br}$

Table V: Correlation analysis of selected parameter with experimental rate constant as a dependent variable for $\mathbf{N}, \mathbf{N}$-disubstituted bromoalkyl amine

\begin{tabular}{|c|c|c|c|c|c|c|c|}
\hline parameters & $\mathbf{a}$ & $\mathbf{b}$ & $\mathbf{R}$ & $\mathbf{p a r a m e t e r s}$ & $\mathbf{a}$ & $\mathbf{b}$ & $\mathbf{R}$ \\
\hline${ }^{*} \mathrm{C}-\mathrm{Br}$ charge & $-3.11 \mathrm{E}-3$ & $-5.10 \mathrm{E}-3$ & 0.990 & $\begin{array}{c}\text { C-Br charge } \\
\text { S.E }\end{array}$ & $-2.79 \mathrm{E}-3$ & $\begin{array}{c}-4.72 \mathrm{E}-3 \\
-1.29 \mathrm{E}-5\end{array}$ & 0.991 \\
\hline C-Br length & $9.77 \mathrm{E}-3$ & $-4.84 \mathrm{E}-3$ & 0.723 & $\begin{array}{c}\text { C-Br charge } \\
\text { Br charge }\end{array}$ & $-2.83 \mathrm{E}-3$ & $\begin{array}{c}-4.63 \mathrm{E}-3 \\
2.77 \mathrm{E}-4\end{array}$ & 0.911 \\
\hline S.E & $9.32 \mathrm{E}-4$ & $-1.32 \mathrm{E}-4$ & 0.872 & $\begin{array}{c}\text { C-Br length } \\
\text { S.E }\end{array}$ & $6.96 \mathrm{E}-3$ & $\begin{array}{c}-3.13 \mathrm{E}-3 \\
-1.05 \mathrm{E}-4\end{array}$ & 0.974 \\
\hline $\mathrm{Br}$ charge & $-5.39 \mathrm{E}-5$ & $2.87 \mathrm{E}-3$ & 0.966 & $\begin{array}{c}\text { C-Br length } \\
\text { Br charge }\end{array}$ & $-1.49 \mathrm{E}-3$ & $\begin{array}{c}7.17 \mathrm{E}-4 \\
3.12 \mathrm{E}-3\end{array}$ & 0.968 \\
\hline $\begin{array}{c}\text { C-Br charge } \\
\text { C-Br length }\end{array}$ & $-5.04 \mathrm{E}-3$ & $\begin{array}{c}-5.59 \mathrm{E}-3 \\
8.17 \mathrm{E}-4\end{array}$ & 0.993 & $\begin{array}{c}\text { S.E } \\
\text { Br charge }\end{array}$ & $1.939 \mathrm{E}-4$ & $\begin{array}{c}-3.52 \mathrm{E}-5 \\
2.29 \mathrm{E}-3\end{array}$ & 0.975 \\
\hline
\end{tabular}

* charge on $\mathrm{C}$ attached to $\mathrm{Br}$

A correlation analysis between the charge at the carbon of ethylene group attached to the bromide atom with experimental values of the rate constants in a series of disubstituted bromoalkyl amine gave a good correlation with values of $\mathrm{R}$ equal 0.963 and 0.99 for $\mathrm{N}$-substituted bromopropyl amines and bromoalkyl amines respectively (Table III \& $\mathrm{V}$ ). While the value of $\mathrm{R}$ for $\mathrm{N}, \mathrm{N}$ - disubstituted bromoethyl and butyl amines are 0.609 and 0.463 respectively. This decrease in value of $\mathrm{R}$ in 
the case of ethyl and butyl amines reveals that in addition to charge on the reaction center there are another factors affecting the reaction rate such as the strain energy, $\mathrm{C}-\mathrm{Br}$ bond length and charge on the bromide group. On the other hand a correlation between charge on the bromide and the rate constant gave the same results.

The strain energy of the molecules and bond length between the C$\mathrm{Br}$ have a less influence on the reaction rate. A multiple correlation shows that the value of $\mathrm{R}$ becomes almost near to unity when two parameters are introduced in the calculations.

\section{CONCLOSION}

Finally it can be conclude that the rate constant of SN2 substitution reaction is mainly affected by correlation parameters introduced in this calculation as on the reaction rate, otherwise can not be done, and also can be used for determining the effects of substituent on these reactions.

\section{REFERENCES}

1) Haeberlien, M. and Murray, J. S.; Brink, T.; Politzer, P.; Can. J. Chem., 70:2209-2214 (1992).

2) Sross, K. C.; Seybold, P. G.; Inter. J. of Quantum Chem., 80: 11071115 (2000).

3) Gross, K. C.; Seybold, P. G.; Hadad, C. M.; Inter. J. of Quantum Chem., 66: 6919-6925 (2001).

4) Gross, K. C.; Seybold, P. G.; Hadad, C. M.; Inter. J. of Quantum Chem., 85:569-579 (2001).

5) Gross, K. C.; Seybold, P. G.; Hadad, C. M.; Inter .J. of Quantum Chem., 90:445-458 (2002).

6) Najim, Z. A.; under press,to be published.

7) Siaeed, M. S.; J. of Education and Science, 17:4-8 (2005).

8) Siaeed, M. S.; Iraqi J. of Science, 31: (1990). 